\title{
The utilization of sodium lignosulphonate extracted from Egyptian rice straw in leather tanning process
}

\author{
A. I. Nasr ${ }^{1, *}$, M. G. Taha², H. Y. Yosef ${ }^{2}$, M. A. El-Shaer ${ }^{2}$ \\ ${ }^{1}$ Department of Wool Production and Technology, Desert Research Center, El Matareya, Cairo, Egypt \\ ${ }^{2}$ Biochemistry Department, Faculty of Agriculture, Al-Azhar University, Cairo, Egypt \\ *Corresponding author. E-mail: ainasr@drc.gov.eg
}

Received: 12 June 2017 Revised: 3 October 2017 Accepted: 4 October 2017

\begin{abstract}
Massive quantities of rice straw are burned annually in Egypt and caused environmental hazards. The present study investigated the utilization of rice straw to produce sodium lignosulphonate (SLS) as a water-soluble derivative of lignin in leather tanning and evaluate its usage as a tanning or re-tanning material as well as its effect on leather quality. The results of testing SLS as a leather tanning agent were unsatisfactory due to its slight effect on shrinkage temperature of leathers, unlike its use as a re-tanning material. Four concentrations of SLS $(0 \%, 5 \%$, $10 \%$, and $20 \%$ ) were used in re-tanning forty of sheep wet-blues. The results showed that using SLS as a re-tanning agent with concentration till 10\% from pelts weight enhances some organoleptic properties, such as fullness and general appearance together with slight improvement in physical properties of leathers. Moreover, the addition of SLS with concentration $20 \%$ led to an excessive swelling in the collagen fibers as shown from depicted scanning electron micrographs and decreased trends of physical properties.
\end{abstract}

Keywords: rice straw, lignin, sodium lignosulphonate, tanning leather.

\section{INTRODUCTION}

Animal skins or hides considered to be byproduct after slaughtering animals. Leather tanning could be regarded as a process using the produced hides to provide basic raw materials for footwear, apparel or other leather goods (Jayathilakan et al., 2012). Leather producers are interested to improve the quality of leathers and increasing their economic values through different natural sources as a safe and environmental friendly tanning and re-tanning materials (UNIDO, 2010; Deselnicu et al., 2012). On the other hand, Egypt produces 5.7 million tons of paddy rice leaving rice straw of about 4 million tons remaining in the fields due to its low nutritional value for livestock feed (FAOSTAT, 2014; Malik et al., 2015). In order to get rid of such quantities of rice straw, farmers used to burn them which resulted in environmental destruction, exacerbate pollution, together with negative impacts on ecosystems and the loss of beneficial soil microorganisms (Kanokkanjana \& Garivait, 2013). The government had to endorse penalties against those farmers to stop such irresponsible action. Another way to tackle this problem is to convince farmers that rice straw could be taken as an income generating material. Rice straw is the most lignocellulosic materials available contains from $16 \%$ to $20 \%$ of lignin-based on dry weight. Crude lignin is very much insoluble in water while it is soluble in acid or alkali to some extent according to the type of lignin (Evstigneev, 2011). Lignosulphonate is one of many water-soluble lignin derivatives, have a wide variety of applications and can be used in leather processing (Sjöström, 1993). It has a high molecular size in similarity with vegetable tannins whereas it has a weak tanning reaction and thus it needs to use it in combination with other aromatic products e.g. phenol, naphthol and formaldehyde as synthetic tannins (Gemei et al., 1980; Kassa, 2014).

Literature for using lignin in leather tanning indicated that the main problem is the insolubility of lignin in water (Gemei et al., 1980). However, some researchers prepared and improved different soluble water derivatives of lignin to be suitable for using in leather tanning (Suparno et al., 2005a and 2005b), while few workers applied them in leather tanning as post-tanning material and studied their effects on collagen fiber and leather properties 
(Kassa, 2014). On the other hand, previous Egyptian investigators interested to maximize the utilization of cellulosic fibers from rice straws to improve paper industry and neglected the other waste which contains a high amount of lignin (Diab, 2007).

Therefore, the present study has three goals; utilization of rice straw to produce lignosulphonate as a water-soluble derivative of lignin in leather tanning and evaluate the usage of lignosulphonates as a tanning or re-tanning material as well as its effect on leather quality.

\section{MATERIALS AND METHODS}

The work plan of this study contained four steps, which were started with extracting lignin from rice straw, preparing sodium lignosulphonate (SLS) from extracted lignin, using SLS in leather tanning and testing leathers as shown in Figure 1. Black liquor was included in this figure since it is available and cheaper as a result of high demand for manufacturers to use crude cellulose in other industries.

\section{Extracting Lignin from Rice Straw}

Kraft process was used in this study to extract lignin from rice straw according to Jingjing (2011). Rice straw was dried for five days in an open and shaded place without using any thermal drying treatment. Dried rice straw was cut into small pieces, screened with length of 19-25 mm, kept in paper bags and then extractive-free wood was prepared.

The preparation of extractive-free wood was done by washing it with ethanol, benzene, and boiling distilled water to be freed up from wax according to TAPPI (2011). Washed straw

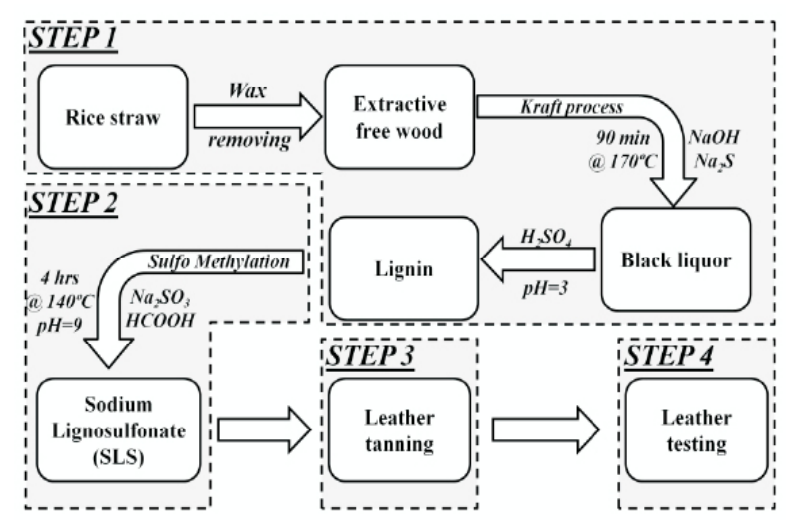

Figure 1. Schematic diagram for the work plan executed in the present study. particles were left to dry at room temperature of about $26^{\circ} \mathrm{C}$. According to Davies (1984), prepared extractive-free wood was used for lignin isolation during Kraft process.

In Kraft process, white liquor consisted of $14 \% \mathrm{NaOH}$ and $35 \% \mathrm{Na}_{2} \mathrm{~S}$, was used at $170{ }^{\circ} \mathrm{C}$ for $90 \mathrm{~min}$ to obtain black liquor. The $\mathrm{pH}$ of the black liquor was adjusted to $\mathrm{pH} 3$ by adding $\mathrm{H}_{2} \mathrm{SO}_{4}(20 \%)$ gradually. The participated lignin was filtered, washed with water for several times, dried at room temperature of about $26^{\circ} \mathrm{C}$, and then ground mechanically.

\section{Preparing SLS from Extracted Lignin}

Lignin is sulfomethylated with a mixture of sodium sulfite and formaldehyde (Kassa, 2014). The addition of formaldehyde and sulfite (molar ratio of $0.6-0.8$ ) to the lignin slurry has increased the $\mathrm{pH}$ from about 4 to 9 . The contents were heated at $140{ }^{\circ} \mathrm{C}$ for about $4 \mathrm{hrs}$ under constant rotation. After cooking, the product was removed, filtered to eliminate insoluble byproducts and then analyzed. The FT-IR spectra of isolated SLS was recorded from 400 to $4000 \mathrm{~cm}^{-1}$, to ensure its chemical structure and fingerprint, using a JASCO 300-E FT-IR spectrometer by scanning 5 times in a resolution of $4 \mathrm{~cm}^{-1}$. The sample was carried out by using the potassium bromide pellet technique (Poletto \& Zattera, 2013).

SLS powder was used to determine ash, moisture, yield percentages, $\mathrm{pH}$, SLS solubility in water, and organic solvents. Moreover, to determine shrinkage temperature, five pieces (10 $\mathrm{cm} \times 10 \mathrm{~cm}$ ) of pickled sheep pelts were tanned with $20 \%$ SLS in the laboratory. Pelts were run in a small glass drum with water at $\mathrm{pH} 4$ and Bé 8 for $30 \mathrm{~min}$. The SLS powder was added and drum was run at speed 8 cycles/min for $8 \mathrm{hrs}$ then stopped overnight. Shrinkage temperature was determined next day in tanned samples and compared with untanned pickled samples (ASTM D-6076).

\section{Using SLS in Leather Tanning}

Forty sheep wet-blues at marketing age were used in this study to evaluate SLS as a re-tanning material. Four concentrations of SLS were used $(0 \%, 5 \%, 10 \%$ or $20 \%)$ in re-tanning wet-blues. Thus, wet-blues were divided randomly into four groups, ten pelts in each group. Leather tanning steps were done at El-Shafei's sons tannery, Alexandria, Egypt according to the executed recipe in Table 1. 
Table 1. Executed recipe for post-tanning wet-blues.

\begin{tabular}{|c|c|c|c|c|}
\hline \multirow{2}{*}{ Step } & \multicolumn{2}{|c|}{ Description } & \multirow{2}{*}{$\begin{array}{l}\text { Time } \\
\text { (min.) }\end{array}$} & \multirow{2}{*}{ Remarks } \\
\hline & $\%$ & Added & & \\
\hline \multirow[t]{2}{*}{ Washing } & 100 & Water & 10 & Drain float \\
\hline & 2 & Soap & & \\
\hline \multirow{2}{*}{ Naturalization } & 100 & Water & 60 & To adjust $\mathrm{pH}=6$ \\
\hline & 2 & $\mathrm{NaHCO}_{3}$ & & \\
\hline \multirow{2}{*}{$\begin{array}{l}\text { Dyeing \& } \\
\text { Re-tanning }\end{array}$} & 3 & Black dye & 90 & Adding lignosulphonate with specified \\
\hline & $\mathrm{X}$ & Lignosulphonate & & percentage. \\
\hline \multirow[t]{2}{*}{ Fatliquoring } & 150 & Water & 90 & \\
\hline & 6 & Fatliquor (fish oil) & & \\
\hline \multirow{2}{*}{ Fixation } & 1 & Formic acid & 30 & \\
\hline & 1 & Formic acid & 60 & \\
\hline Washing & 100 & Water & 10 & Out $\&$ overnight as horse up then samming. \\
\hline Finishing & -- & -- & -- & Drying in shaded place. \\
\hline
\end{tabular}

\section{Testing Leathers}

All finished leathers were assessed for softness, grain smoothness, grain tightness, fullness, and general appearance by standard tangible evaluation technique (Kasmudjiastuti \& Murti, 2017). Three experienced tanners rated the leathers on a scale of 1-10 points for each functional property (higher points indicate a superior property). The average of the three tanners was recorded for each sample.

Qualitative and operational properties of the obtained leathers were assessed according to indices of chemical analysis, physicomechanical analysis of the finished leather. Thickness, tensile strength, elongation, split tear strength, $\mathrm{pH}$, ash, and moisture were analyzed (ASTM, 2014). In addition, the morphological characteristics of tanned leathers were analyzed using JEOL JSM5300LV Scanning Electron Microscopy (SEM). Samples were cut from official sampling position (ASTM- D2813). The specimens were cut with a uniform thickness without any pre-treatment. The micrograph of the cross section was obtained by operating the SEM.

\section{Statistical Analysis}

Data were analyzed using GLM procedure of SAS (2008) to evaluate the differences among produced leathers. The following model was used in the analysis:

$$
\mathrm{Y}_{\mathrm{ij}}=\mu+\mathrm{T}_{\mathrm{i}}+\mathrm{e}_{\mathrm{ij}}
$$

Where $Y_{i j}$ is the observation taken on finished leather, $\mu$ is overall mean, $T_{i}$ is a fixed effect of the $\mathrm{i}^{\text {th }}$ SLS concentration treatment $(1=0 \%, 2=5 \%$, $3=10 \%$ and $4=20 \%$ ) and $\mathrm{e}_{\mathrm{ij}}$ is the random error assumed to be normally distributed with mean $=0$ and variance $=\sigma^{2}$.

\section{RESULTS AND DISCUSSION \\ FT-IR Analysis of Sodium Lignosulphonate (SLS)}

The FT-IR spectrum of prepared SLS was given in Figure 2. The fingerprint region lied between wave numbers ranging from $600 \mathrm{~cm}^{-1}$ to $1700 \mathrm{~cm}^{-1}$ and typical stretching of chemical groups was observed at $2800 \mathrm{~cm}^{-1}$ to $3500 \mathrm{~cm}^{-1}$. As presented in Table 2, the broad band at $3398 \mathrm{~cm}^{-1}$ was due to the presence of hydroxyls. The band at $2960 \mathrm{~cm}^{-1}$ was contributed to methylene and methyl groups. The adsorption of aromatic methoxy group was located at $2854 \mathrm{~cm}^{-1}$. At fingerprint region, the ad-

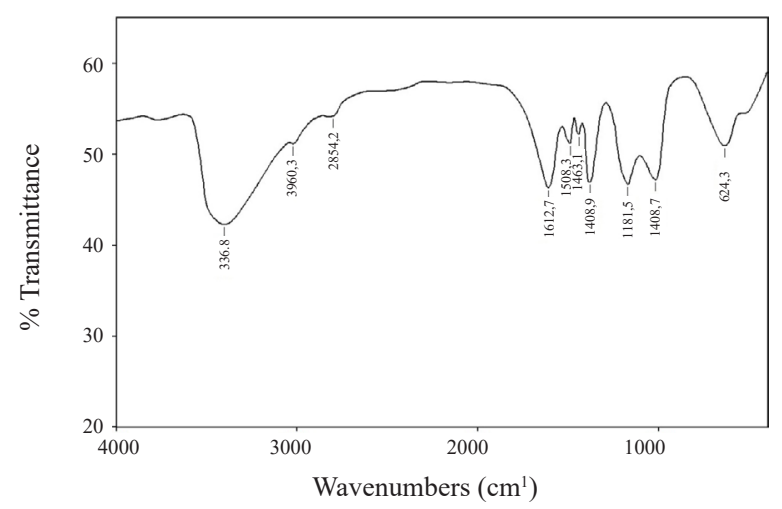

Figure 2. The FT-IR spectrum of prepared sodium lignosulphonate (SLS). 
Table 2. The assignment list of infrared bands of sodium lignosulphonate.

\begin{tabular}{cl}
\hline $\begin{array}{c}\text { Absorption } \\
\text { peak }\left(\mathrm{cm}^{-1}\right)\end{array}$ & \multicolumn{1}{c}{ Band } \\
\hline 3398 & $\mathrm{O}-\mathrm{H}$ stretching vibration \\
2960 & $\mathrm{C}-\mathrm{H}$ stretching \\
2854 & $\mathrm{C}-\mathrm{H}$ vibration of methyl group \\
1612 & $\mathrm{C}=\mathrm{C}$ ring skeletal vibration \\
1508 & $\mathrm{C}-\mathrm{C}$ ring skeletal vibration \\
1463 & $\mathrm{C}-\mathrm{H}$ vibration \\
1408 & $\mathrm{C}-\mathrm{H}$ ring skeletal deformation \\
1181 & $\mathrm{C}-\mathrm{O}$ stretching \\
1048 & $-\mathrm{SO}_{3}$ adsorption \\
624 & $-\mathrm{SO}_{3}$ deformation \\
\hline
\end{tabular}

sorption bands at $1612 \mathrm{~cm}^{-1}$ and $1508 \mathrm{~cm}^{-1}$ were characteristic of phenyl ring skeletal vibrations of lignin macromolecules. The vibrations of methylene and methyl groups were bands at $1463 \mathrm{~cm}^{-1}$ and $1408 \mathrm{~cm}^{-1}$. The bands at 1048 and $624 \mathrm{~cm}^{-1}$ were assigned to the adsorption and deformation of sulfonated group, respectively. These bands were in agreement with corresponding bands obtained for lignin and lignosulphonate by other researchers (Kamoun et al., 2003; Diab, 2007; Shen et al., 2008; Zhili \& Yuanyuan, 2011; Poletto \& Zattera, 2013 and Darweesh, 2014). These results might suggest that the obtained extract of this study is for lignosulphonate.

\section{SLS Properties}

The properties of SLS powder were determined and presented in Table 3. Ash, moisture percentages and $\mathrm{pH}$ values were $9.8 \%$, $3.9 \%$ and $9 \%$ respectively, which appeared to be close to the corresponding values obtained by other investigators (Diab, 2007; Jingjing, 2011). Obviously, the obtained SLS was soluble in water and characterized by high yield (68.88\%). Due to chemical structure of lignosulphonate, it is an organic material with a high molecular weight such as in vegetable tanning materials (Covington, 2009). Usually, shrinkage temperature of vegetable tanning materials ranges from $70^{\circ} \mathrm{C}$ to $85^{\circ} \mathrm{C}$ and considered to be the weakest tanning materials (BASF, 2007). Therefore, SLS was lower than vegetable tanning material in shrinkage temperature $\left(63^{\circ} \mathrm{C}\right)$, thus, the present results excluded the possibility of using it as a main tanning material in leather tanning. On the other hand, the colors of SLS powder and pickled pelt treated with 20\% SLS were dark and light brown respectively, which considered to be acceptable color in leather tanning such as vegetable tanning materials (BASF, 2007).

\section{Organoleptic Properties}

Table 4 presents organoleptic properties for the control (SLS 0\%) and treated leathers (SLS $5 \%, 10 \%$ and $20 \%$ ). Leathers treated with $10 \%$ SLS showed the highest general appearance, where other leathers were similar in this property. With

Table 3. Properties of sodium lignosulphonate (SLS) powder.

\begin{tabular}{lc}
\hline Parameter & Value \\
\hline Ash & $9.8 \%$ \\
Moisture & $3.9 \%$ \\
$\mathrm{pH}$ & 9 \\
Yield* & $68.88 \%$ \\
Solubility in water & Soluble \\
Solubility in organic solvents** & Soluble \\
Color of SLS powder & Dark brown \\
Color of pelts treated with $20 \% \mathrm{SLS}$ & Light brown \\
Shrinkage temperature of pickled pelt $\left(\mathrm{T}_{\mathrm{S} 1}\right)$ & $48{ }^{\circ} \mathrm{C}$ \\
Shrinkage temperature of tanned pelt with $20 \% \mathrm{SLS}\left(\mathrm{T}_{\mathrm{S} 2}\right)$ & $63{ }^{\circ} \mathrm{C}$ \\
$\Delta \mathrm{T}_{\mathrm{S}}=\left(\mathrm{T}_{\mathrm{S} 2}-\mathrm{T}_{\mathrm{S} 1}\right)$ & $15{ }^{\circ} \mathrm{C}$ \\
\hline
\end{tabular}

* Yield calculated as percentage from lignin in black liquor.

** Organic solvents were acetone, alcohols, chloroform, hexane and ethyl acetate. 
Table 4. Organoleptic properties of control and treated tanned leathers with different concentrations of sodium lignosulphonate (SLS).

\begin{tabular}{lcccc}
\hline \multirow{2}{*}{ Property } & Control & \multicolumn{3}{c}{ Treated } \\
\cline { 2 - 5 } & SLS 0\% & SLS 5\% & SLS 10\% & SLS 20\% \\
\hline Fullness & 7 & 8 & 9 & 10 \\
Grain tightness & 7 & 7 & 8 & 9 \\
Grain smoothness & 8 & 8 & 7 & 6 \\
Softness & 9 & 9 & 7 & 6 \\
General appearance & 8 & 8 & 9 & 8 \\
\hline
\end{tabular}

respect to other organoleptic properties, fullness and grain tightness properties tend to increase by increasing SLS concentration, while the opposite trend was observed with grain smoothness and softness properties. That might be due to similar effect of SLS with vegetable tanning material as an organic tanning material as a result of swelling in collagen fibers, increase their hardness and also increase roughness in surface layer of finished leathers (Heidemann, 1993; Covington, 2009). As far as organoleptic properties, it is obvious that the treated leathers with SLS 5\% and 10\% were close in most organoleptic properties. The superiority of SLS $10 \%$ leathers might due to its high general appearance property, while SLS 20\% leathers had the lowest values among treated leathers.

\section{Physical and Chemical Properties}

Physical and chemical properties of control and treated tanned leathers were presented in Table 5. All properties differed significantly as a result of addition of SLS as a re-tanning material. The treated leathers (SLS 5\%, 10\%, and 20\%) had higher thickness values $(\mathrm{P}<0.05)$ than control leathers (SLS 0\%), where the differences among treated leathers were not significant. Regarding physical properties, tensile and tearing strength values tend to significantly decrease $(\mathrm{P}<0.01)$ in $20 \%$ SLS leathers, whereas leathers treated with $0 \%, 5 \%$ and $10 \%$ SLS showed no significant differences. This trend was expected due to swelling and fullness effects of SLS in addition to the negative relation between thickness and strength (Kotb, 1987; Abdelsalam et al., 1998). The percentages of elongation tend to decrease by increasing SLS concentration, which might be due to increase collagen fiber hardness (Heidemann, 1993; Covington, 2009).

Chemical properties showed that $\mathrm{pH}$ and ash percentage values increased significantly $(\mathrm{P}<0.01)$ between the control and treated leathers because of the effect of alkalinity and the content of ash in SLS powder (Table 3). For this reason, $\mathrm{pH}$ and ash values tended to increase by increasing SLS concentration.

As far as physical properties of tanned leather,

Table 5. Physical and chemical properties of control and treated tanned leathers with different concentrations of sodium lignosulphonate (SLS).

\begin{tabular}{|c|c|c|c|c|c|c|c|}
\hline \multirow{2}{*}{ Property } & \multirow{2}{*}{ ASTM } & \multirow{2}{*}{$\begin{array}{l}\text { Control } \\
\text { SLS 0\% } \\
\end{array}$} & \multicolumn{3}{|c|}{ Treated } & \multirow{2}{*}{ SEM } & \multirow{2}{*}{ Significanc } \\
\hline & & & SLS 5\% & SLS $10 \%$ & SLS $20 \%$ & & \\
\hline \multicolumn{8}{|c|}{ Physical properties } \\
\hline Thickness (mm) & D1813 & $1.17^{\mathrm{b}}$ & $1.35^{\mathrm{a}}$ & $1.41^{\mathrm{a}}$ & $1.43^{\mathrm{a}}$ & 0.31 & $*$ \\
\hline Tensile $\left(\mathrm{kg} / \mathrm{cm}^{2}\right)$ & D2209 & $283.60^{\mathrm{a}}$ & $284.02^{\mathrm{a}}$ & $291.96^{\mathrm{a}}$ & $222.06^{\mathrm{b}}$ & 6.72 & $* *$ \\
\hline Tearing $(\mathrm{kg} / \mathrm{cm})$ & D4704 & $40.28^{\mathrm{a}}$ & $42.42^{\mathrm{a}}$ & $35.88^{\mathrm{a}}$ & $26.20^{b}$ & 0.98 & $* *$ \\
\hline Elongation $(\%)$ & D2211 & $65.25^{\mathrm{bc}}$ & $84.89^{\mathrm{a}}$ & $76.73^{\mathrm{ab}}$ & $55.93^{c}$ & 2.52 & $* *$ \\
\hline \multicolumn{8}{|c|}{ Chemical Properties } \\
\hline $\mathrm{pH}$ & D2810 & $3.63^{\mathrm{c}}$ & $4.34^{\mathrm{b}}$ & $4.59^{\mathrm{ab}}$ & $4.81^{\mathrm{a}}$ & 0.11 & $* *$ \\
\hline Moisture (\%) & D6403 & $17.26^{\mathrm{a}}$ & $15.78^{\mathrm{a}}$ & $16.40^{\mathrm{a}}$ & $14.01^{\mathrm{b}}$ & 0.35 & $*$ \\
\hline Ash (\%) & D2617 & $5.44^{\mathrm{a}}$ & $6.61^{\mathrm{b}}$ & $7.51^{\mathrm{c}}$ & $8.26^{\mathrm{d}}$ & 0.26 & $* *$ \\
\hline
\end{tabular}



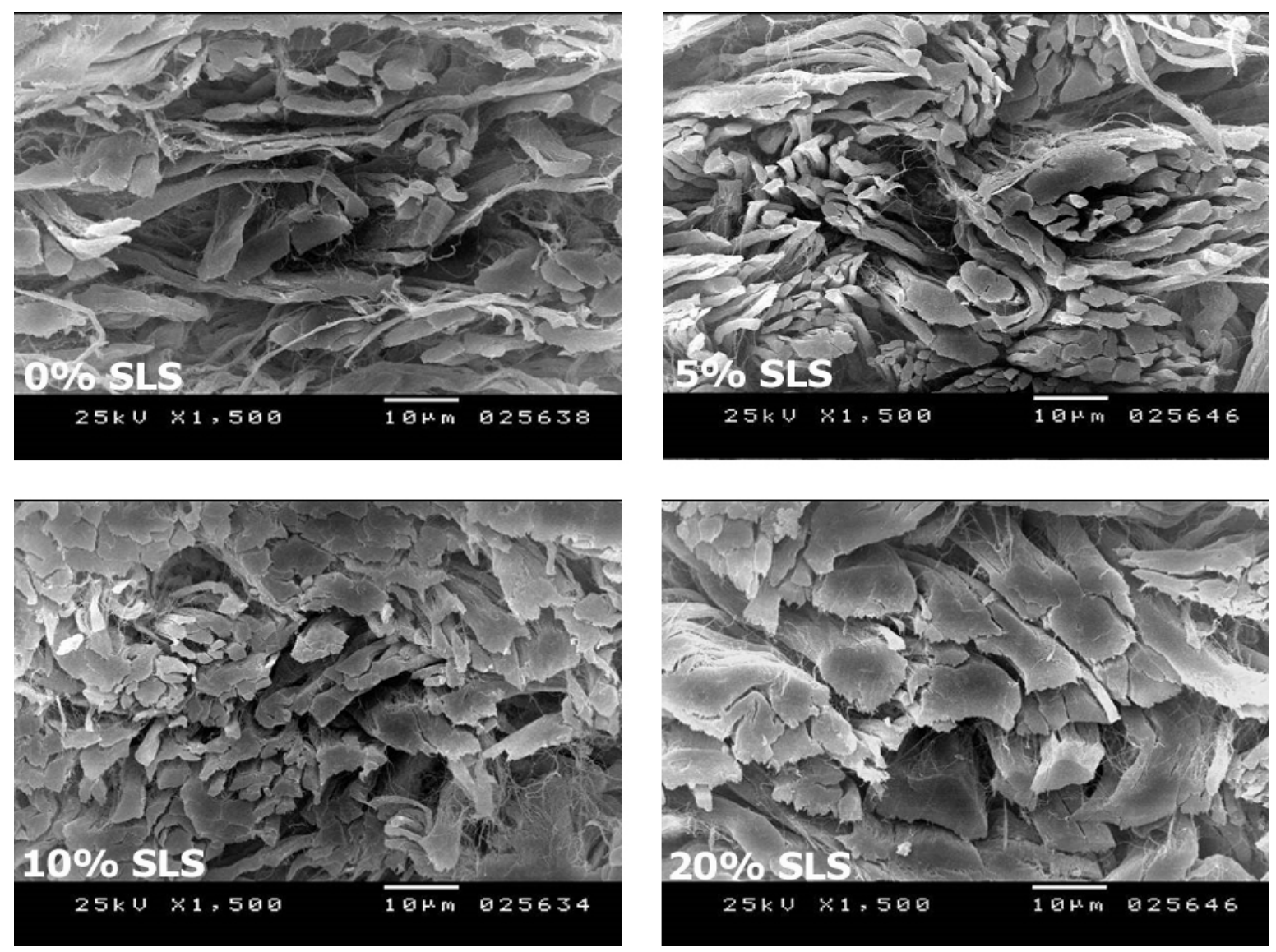

Figure 3. Scanning electron micrographs (magnification of $1500 \mathrm{X}$ ) for treated tanned leathers with different concentrations of sodium lignosulphonate (SLS).

it is observed that addition of SLS with concentrations of $5 \%$ and $10 \%$ would improve physical properties, while the concentration of $20 \%$ would deteriorate such properties (Table 5). The high concentration of SLS $(20 \%)$ might lead to weaken leathers as a negative effect of excess swelling on collagen fiber.

\section{Scanning Electron Microscopy}

Figure 3 shows the depicted micrographs from the cross-section of tanned leathers treated with different concentrations of SLS. The control leathers $(0 \%$ SLS) showed the highest separation of fibers, while increasing the concentration of SLS led to decrease the spaces among fiber bundles due to fiber swelling, which increased the fibers diameters to about the double in $20 \%$ SLS leathers. This extra increase in fiber swelling and compactness in $20 \%$ SLS leathers resulted in increasing in some other properties such as thickness, fullness and grain tightness and decreasing tensile strength, tearing strength and softness. On the other hand, 5\% and 10\%
SLS leathers showed moderate changes in fiber swelling and compactness, which explained the improvement occurred on their organoleptic and physical properties, especially concentration $10 \%$ of SLS as described previously.

\section{CONCLUSIONS}

Using sodium lignosulphonate (SLS) extracted from Egyptian rice straw in leather tanning was investigated. The solubility of SLS in water allows its utility in leather tanning. The addition of SLS with concentration $20 \%$ from pelts weight led to an excessive swelling in the collagen fibers and thus caused a decrease in physical properties of leathers, but SLS can be used as a re-tanning agent with concentration till $10 \%$ to improve leather quality. SLS enhances some organoleptic properties, such as fullness and general appearance together with slight improvement in physical properties of leathers. Therefore, producing SLS considered to be an important complementary step for Kraft process in other industries which might be suitable in Egypt in order to reduce some envi- 
ronmental hazards and on other hand enhance the profitability of leather industry.

\section{ACKNOWLEDGEMENT}

Authors would like to thank Eng. Mohamed El-Shafei, director of El-Shafei's sons tannery, Alexandria, Egypt for his help and support in the practical part of this study.

\section{REFERENCES}

Abdelsalam, M. M., El-Gabbas, H. M., \& Abdelaziz, N. M. (1998). Physical properties of raw hides and leather of the Egyptian Camel. Alexandria Journal of Agricultural Research, 43, 3-19.

ASTM. (2014). Books of standards Vol.15.04. USA: American Society for Testing and Materials.

BASF. (2007). Pocket book for leather technologist ( $4^{\text {th }}$ ed.). 67056 Ludwigshafen, Germany: Badische Anilin- und Soda-Fabrik.

Covington, A. D. (2009). Tanning chemistry the science of leather. Cambridge, London: RSC publishing.

Darweesh, H. H. M. (2014). Utilization of $\mathrm{Ca}-$ lignosulphonate prepared from black liquor waste as a cement super plasticizer. Journal of Chemistry and Materials Research, 1, 28-34.

Davies, R. D. (1984). Pulp and paper manufacture: an industry of the future. South African Journal of Science, 80, 109-15.

Deselnicu, V., Crudu, M., Ioannidis, I. \& Deselnicu, D. C. (2012). Synthetic organic tanning systems. Bucharest, Romania: Fourth International Conference on Advanced Materials and Systems. $27^{\text {th }}-29^{\text {th }}$ September.

Diab, M. A. (2007). Separation and characterization of lignin obtained from karft puling black liquor of ligno cellulosic materials (Thesis). Alexandria University, Faculty of Science, Egypt.

Evstigneev, E. I. (2011). Factors affecting lignin solubility. Russian Journal of Applied Chemistry, 84, 1040-1045.

FAOSTAT. (2014). Production-Crops data. World Food And Agriculture Organization.

Gemei, M. S., Makar, S. M., \& Saleh, M. S. E. (1980). Derivatives of lignin as synthetic tanning agents. Die Angewandte Makromolekulare Chemie, 92(1404), 1-14, https://doi.org/10.1002/apmc.1980.050920101

Heidemann, E. (1993). Fundamentals of leather manufacture. Darmstadt, Germany: Eduard Roether KG Druckerei und Verlag.

Jayathilakan, K., Sultana, K., Radhakrishna, K., \& Bawa, A.S. (2012). Utilization of byproducts and waste materials from meat, poultry and fish processing industries: a review. Journal of Food Science and Technology, 49, 278-93.

Jingjing, L. (2011). Isolation of lignin from wood
(Thesis). Saimaa Univirsty of Applied Science, Faculty of Techlogy, Imatra, Finland.

Kamoun, A., Jelidi, A. \& Chaabouni, M. (2003). Evaluation of the performance of sulfonated esparto grass lignin as a plasticizer-water reducer for cement. Cement and Concrete Research, 33, 995-1003.

https://doi.org/10.1016/S0008-8846(02)01098-0

Kanokkanjana, K. \& Garivait, S. (2013). Alternative rice straw management practices to reduce field open burning in thailand. International Journal of Environmental Science and Development, 4, 11923.

Kasmudjiastuti, E. \& Murti, R.S. (2017). The effects of finish type on permeability and organoleptic properties of python (Python reticulatus) skin finished leather. Majalah Kulit, Karet, dan Plastik, 33(1), 19-28. https://doi.org/10.20543/mkkp.v33i1.1575

Kassa, T. (2014). Manufacturing of synthetic tanning agent from kraft lignin (Thesis). Addis Ababa University, Ethiopia.

Kotb, A. A. (1987). Studies on physical and histological properties of hides and skins of farm animals (Thesis). Alexandria University, Faculty of Agriculture, Egypt.

Malik, K., Tokkas, J., Anand, R. C. \& Kumari, N. (2015). Pretreated rice straw as an improved fodder for ruminants-An overview. Journal of Applied and Natural Science, 7, 514-20.

Poletto, M. \& Zattera, A. J. (2013). Materials produced from plant biomass part III: Degradation kinetics and hydrogen bonding in lignin. Materials Research, 16, 1065-70.

SAS. (2008). SAS/STAT 9.2 User's guide (2nd ed.). SAS Institute Inc., Cary, NC.

Shen, Q., Zhang, T., \& Zhu, M. F. (2008). A comparison of the surface properties of lignin and sulfonated lignins by FTIR spectroscopy and wicking technique. Colloids and Surfaces A: Physicochemical and Engineering Aspects, 320, 57-60, https://doi.org/10.1016/j.colsurfa.2008.01.012

Sjöström, E. (1993). Wood chemistry, fundamentals and applications (2nd ed.). USA: Gulf Professional Publishing, Academic Press.

Suparno, O., Covington, A. D. \& Evans, C. S. (2005a). Kraft lignin degradation products for tanning and dyeing of leather. Journal of Chemical Technology and Biotechnology, 80, 44-49, https://doi.org/10.1002/jctb.1150

Suparno, O., Covington, A. D., Phillips, P. S., \& Evans, C. S. (2005b). An innovative new application for waste phenolic compounds: Use of Kraft lignin and naphthols in leather tanning. Resources, Conservation and Recycling, 45, 114-27. https://doi.org/10.1016/j.resconrec.2005.02.005 
TAPPI. (2011). Preparation of wood for chemical analysis, T 264 CM-07. Technical Association of the Pulp \& Paper Industry.

UNIDO. (2010). Future trends in the world leather and leather products industry and trade. Vienna: United Nations Industrial Development Organization.
Zhili, L. \& Yuanyuan, G. (2011). Extraction of lignin from sugar cane bagasse and its modification into a high performance dispersant for pesticide formulations. Journal of the Brazilian Chemical Society, 22, 1866-1871.

https://doi.org/10.1590/S0103-50532011001000006 